\title{
Brief communication: Impact of the recent atmospheric circulation change in summer on the future surface mass balance of the Greenland ice sheet
}

\author{
A. Delhasse ${ }^{1}$, X. Fettweis ${ }^{1}$, C. Kittel ${ }^{1}$, C. Amory ${ }^{1}$, and C. Agosta ${ }^{1,2}$ \\ ${ }^{1}$ Laboratory of Climatology, Department of Geography, University of Liège, Liège, Belgium \\ ${ }^{2}$ LSCE, University of Paris Saclay, Gif-sur-Yvette, France \\ Correspondence to: Alison Delhasse (alison.delhasse@uliege.be)
}




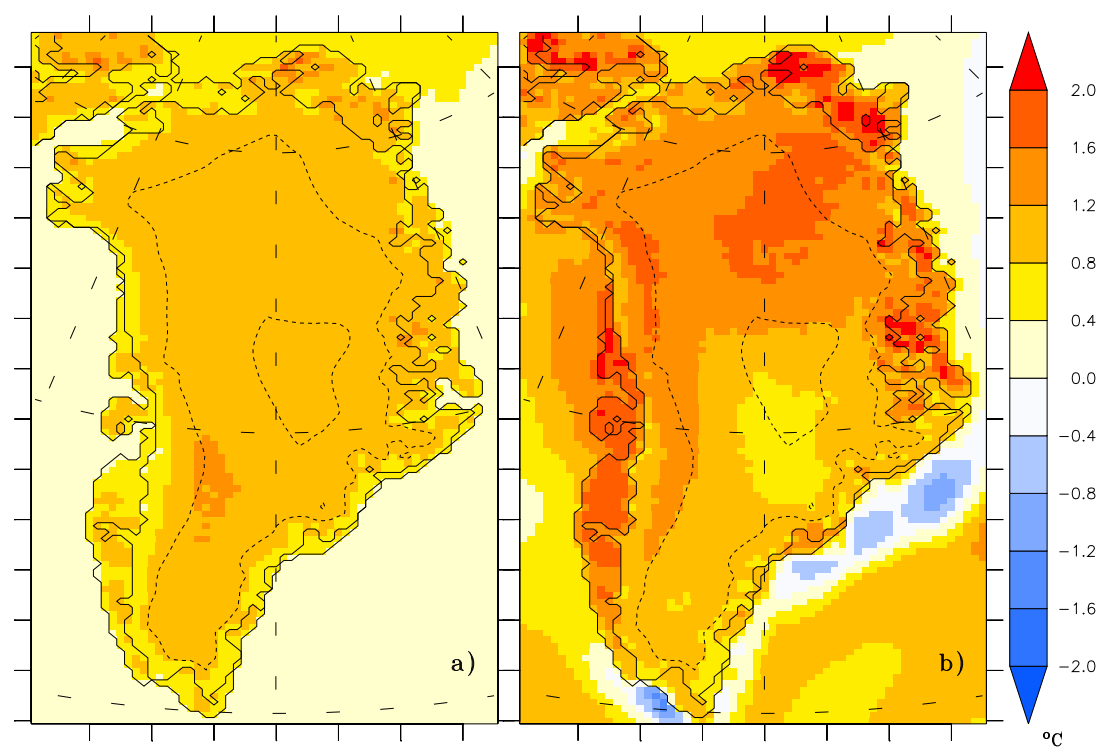

Figure S1. Mean anomalies of JJA near-surface temperature $\left({ }^{\circ} \mathrm{C}\right)$ of MAR forced with ERA-Interim warmer of $+1{ }^{\circ} \mathrm{C}$ over a) $1980-1999$ and b) 2000 - 2016 compared to MAR forced with unaltered ERA-Interim over 1980 - 1999. Dashed lines are equal altitude lines of 2000 $\mathrm{m}$ and $3000 \mathrm{~m}$. 


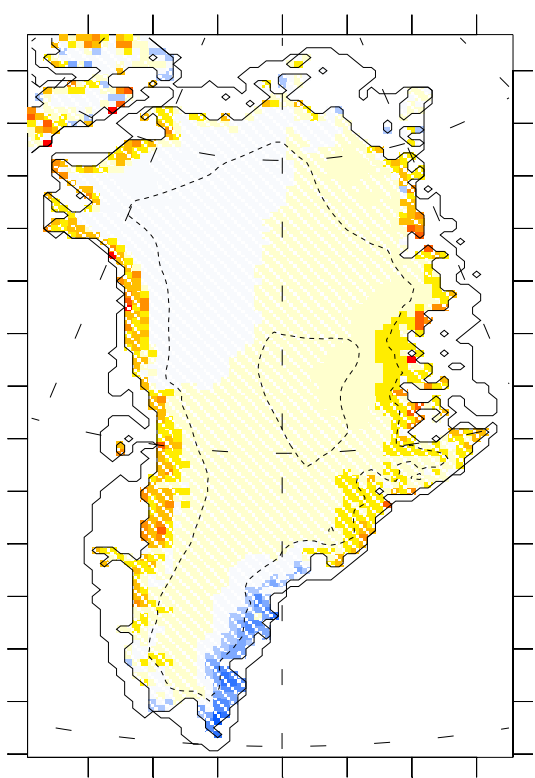

a) MARera+1 - MARcan+1

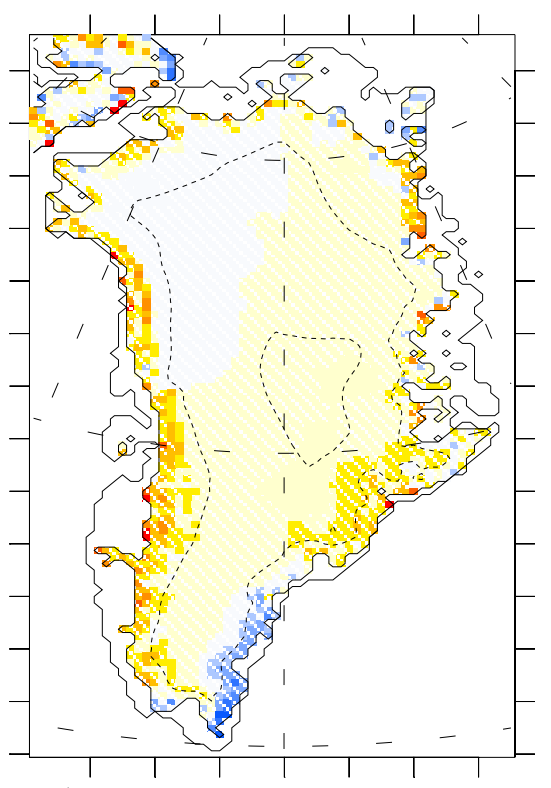

b) MARera +1.5 - MARcan +1.5

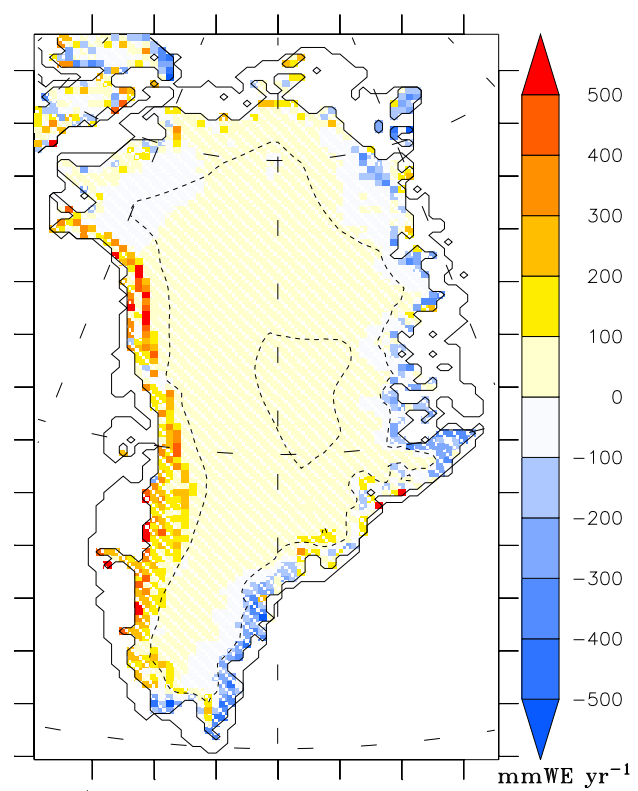

c) MARera+1.5 - MARcan+2

Figure S2. Differences of mean anomalies of annual SMB (in mmWE $y^{-1}$ ) between a) MARera+1 and MARcan+1, b) MARera+1.5 and MARcan+1.5 and c) MARera+2 and MARcan+2. Areas where anomaly differences are smaller than the inter-annual variability (i.e. the standard deviation) of the simulation of MAR forced by unaltered ERA-Interim over 1980 - 1999 are hatched. Dashed lines are equal altitude lines of $2000 \mathrm{~m}$ and $3000 \mathrm{~m}$. See Table S1 and Table S2 for abbreviations.

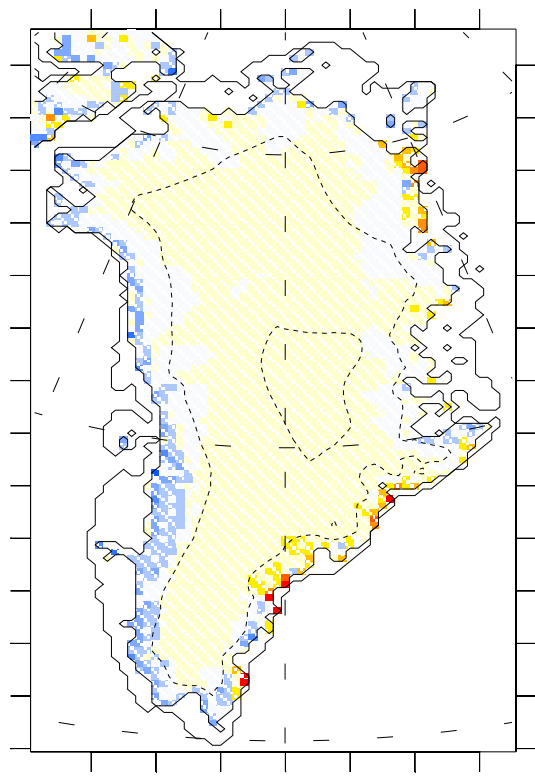

a) MARera+1 - MARnor+1

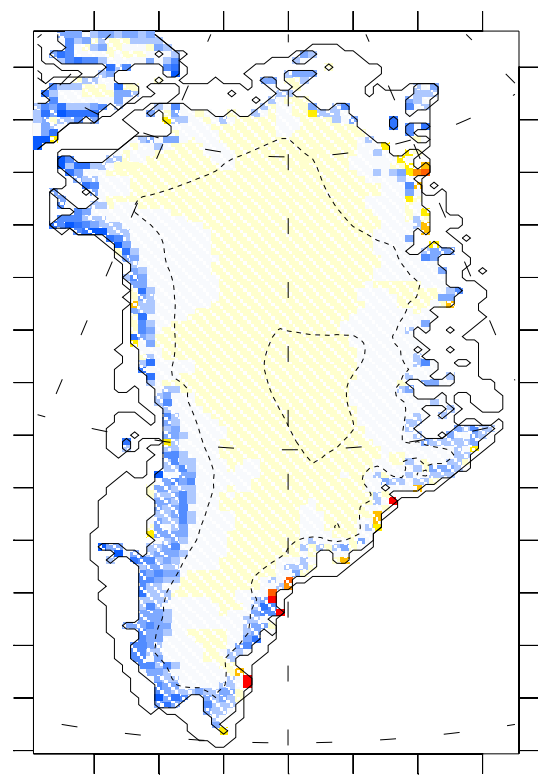

b) MARera +1.5 - MARnor +1.5

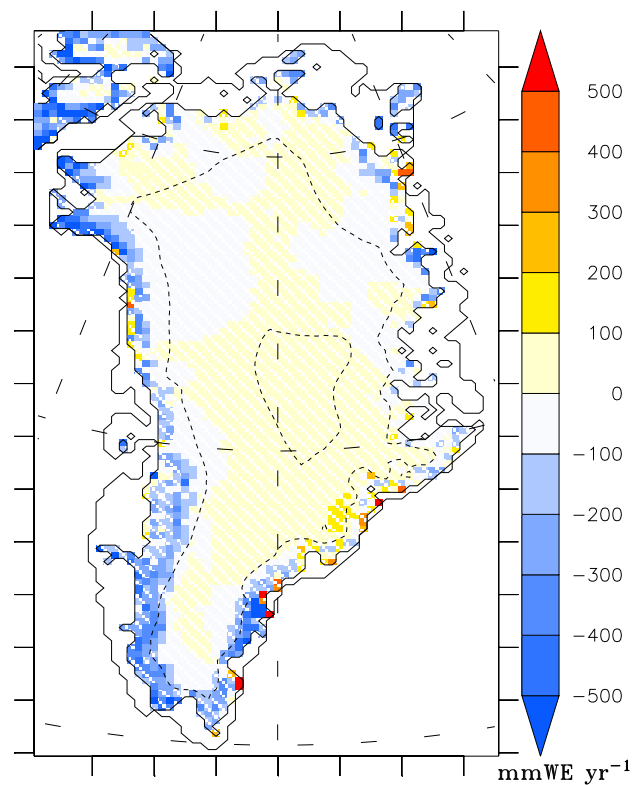

c) MARera +1.5 - MARnor +2

Figure S3. Same as Fig. S2 but for MARnor+x where x equals 1,1.5 or 2 . 


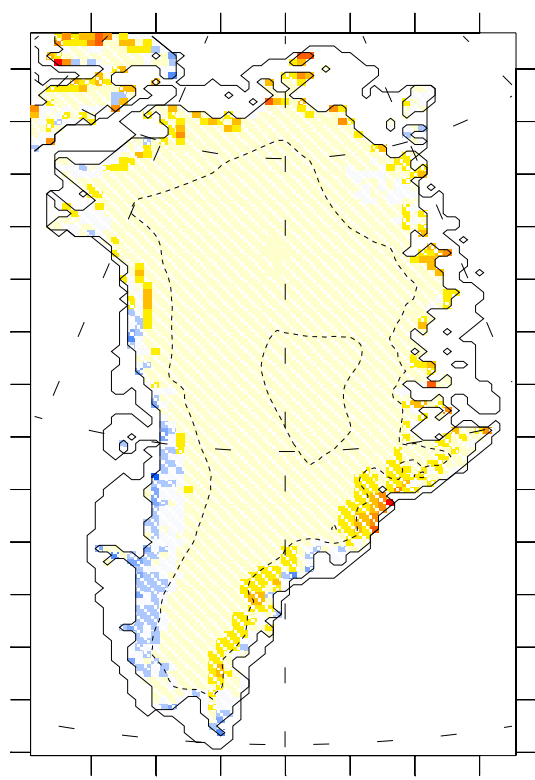

a) MARera+1 - MARmir+1

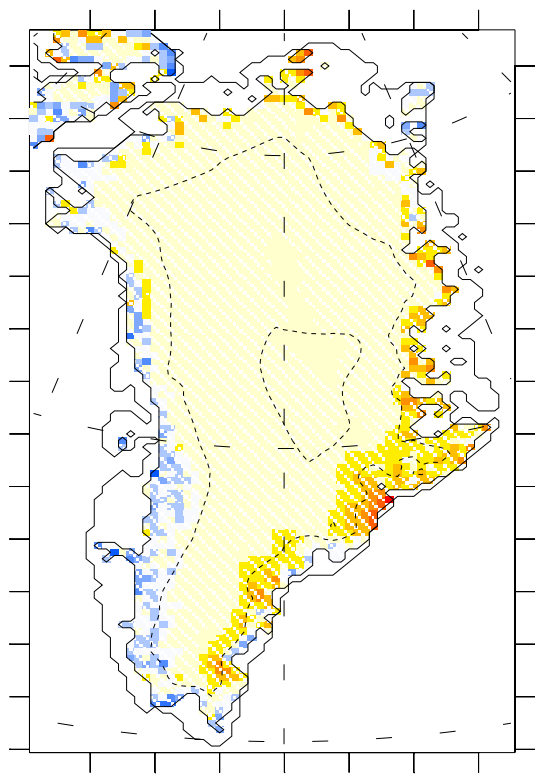

b) MARera $+1.5-$ MARmir +1.5

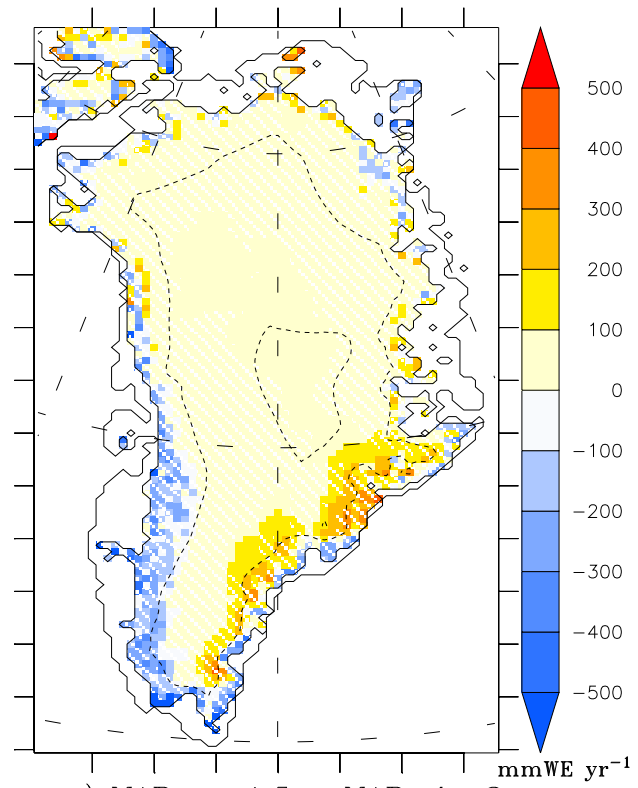

c) MARera+1.5 - MARmir +2

Figure S4. Same as Fig. S2 but for MARmir+x where x equals 1,1.5 or 2. 


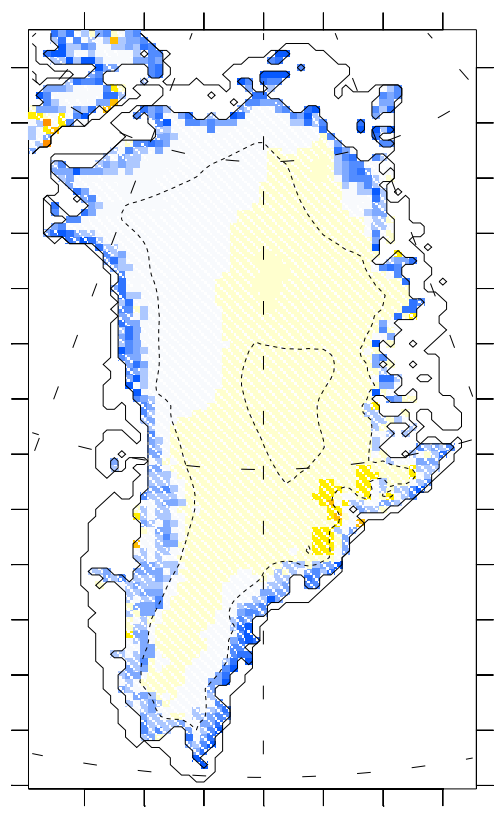

a) MARera2k+1 - MARcan+1.5

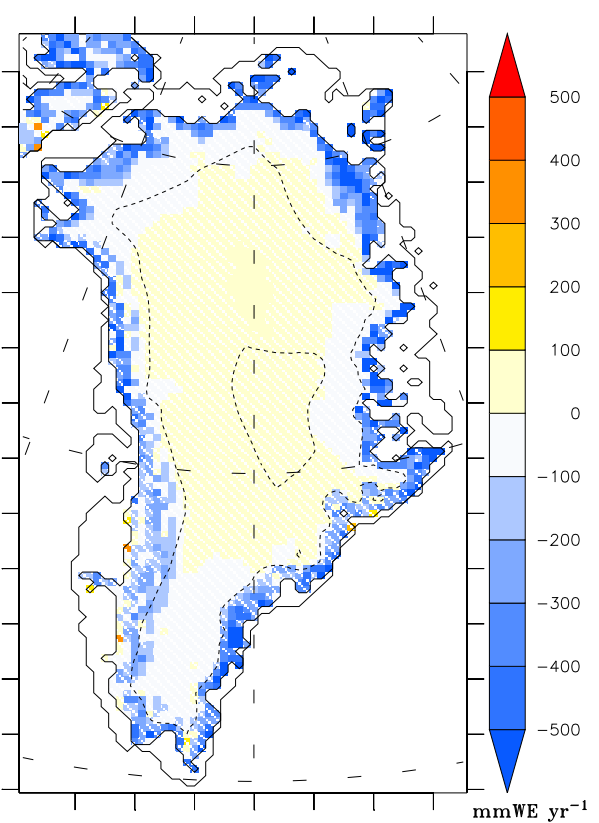

b) MARera2k+1.5 - MARcan +2

Figure S5. Differences of mean anomalies of annual SMB (in mmWE $\mathrm{y}^{-1}$ ) between a) MARera2K+1 and MARcan+1.5 and b) MARera2K+1.5 and MARcan+2. Areas where anomaly differences are smaller than the inter-annual variability (i.e. the standard deviation) of the simulation of MAR forced by unaltered ERA-Interim over 1980 - 1999 are hatched. Dashed lines are equal altitude lines of 2000 m and $3000 \mathrm{~m}$. See Table S1 and Table S2 for abbreviations. 


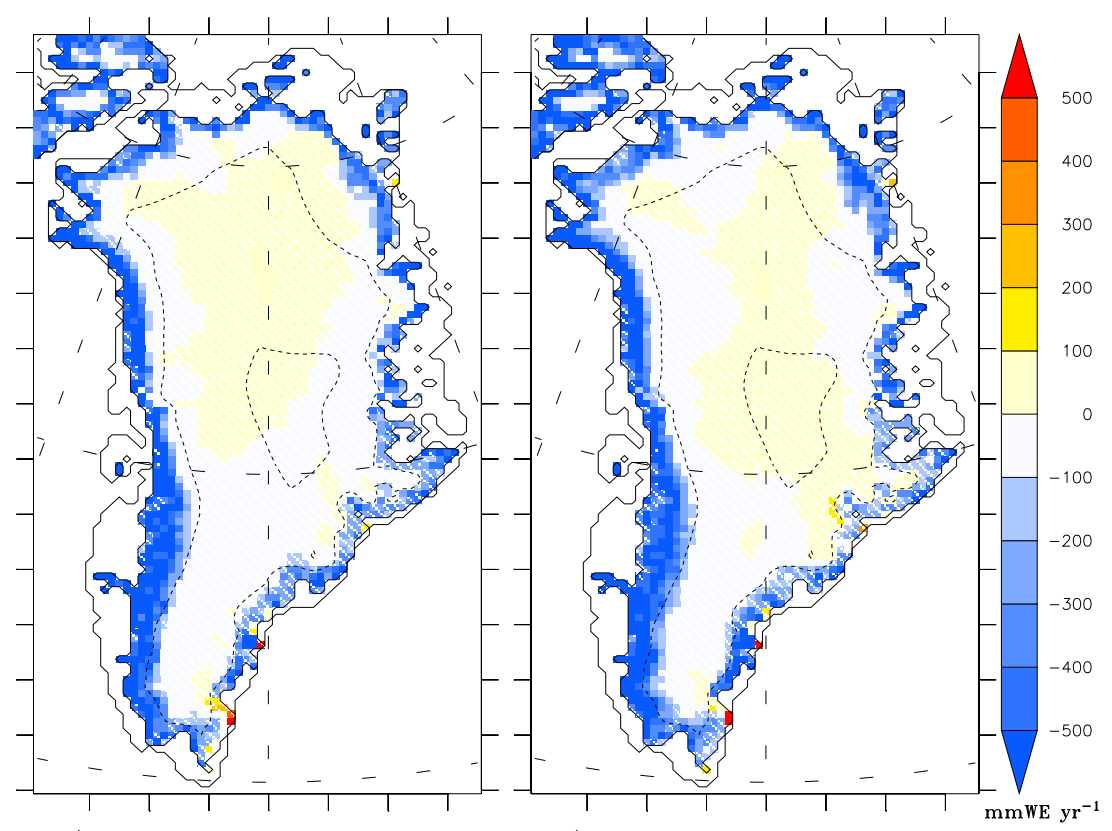

a) MARera2k+1 - MARnor +1.5

b) MARera2k + 1.5 - MARnor+2

Figure S6. Same as Fig. S5 but for MARnor+x where x equals 1.5 or 2.

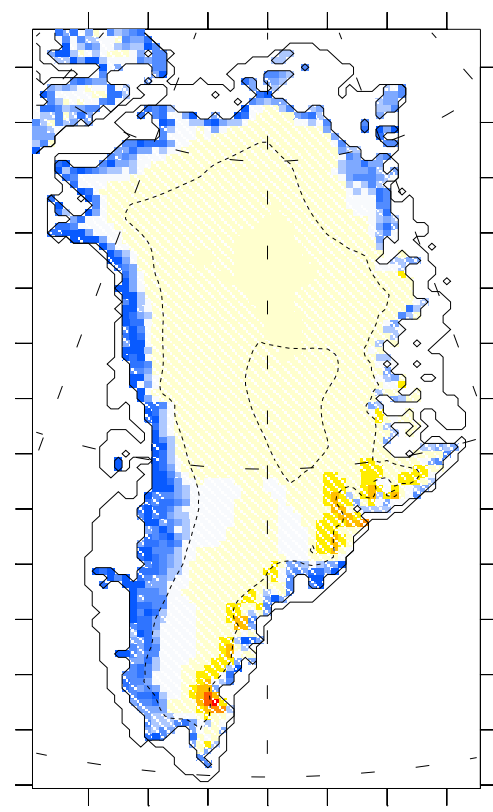

a) MARera2k +1 - MARmir +1.5

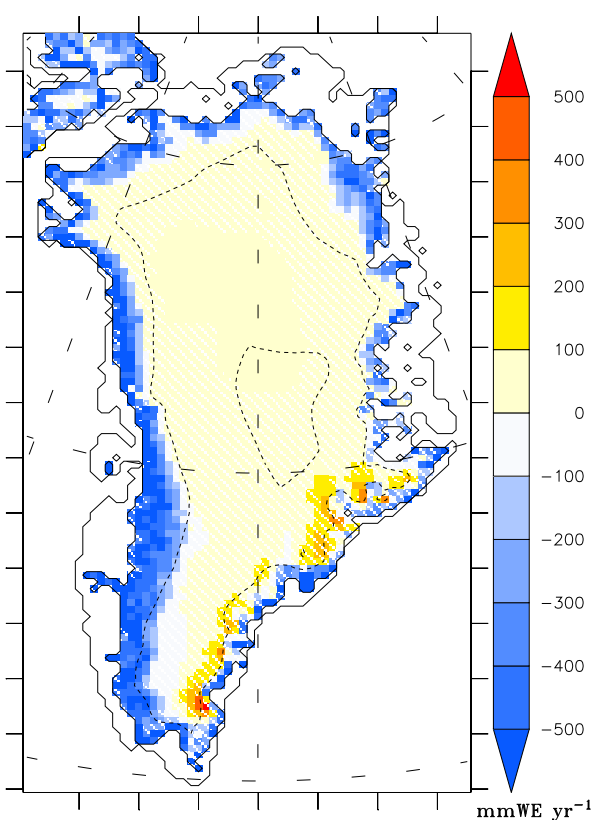

b) MARera2k+1.5 - MARmir+2

Figure S7. Same as Fig. S5 but for MARmir+x where x equals 1.5 or 2. 
Table S1. Abbreviation description of reanalysis sensitivity experiments

\begin{tabular}{ll}
\hline MARera+1 & $\begin{array}{l}\text { Anomalies between MAR forced with the ERA-Interim reanalysis warmer of }+1{ }^{\circ} \mathrm{C} \text { over } 1980-1999 \text { and } \\
\text { MAR forced with the unaltered ERA-Interim reanalysis over } 1980-1999\end{array}$ \\
\hline MARera+1.5 & $\begin{array}{l}\text { Anomalies between MAR forced with the ERA-Interim reanalysis warmer of }+1.5^{\circ} \mathrm{C} \text { over } 1980-1999 \text { and } \\
\text { MAR forced with the unaltered ERA-Interim reanalysis over } 1980-1999\end{array}$ \\
\hline MARera+2 & $\begin{array}{l}\text { Anomalies between MAR forced with the ERA-Interim reanalysis warmer of }+2{ }^{\circ} \mathrm{C} \text { over } 1980-1999 \text { and } \\
\text { MAR forced with the unaltered ERA-Interim reanalysis over } 1980-1999\end{array}$ \\
\hline MARera2k & $\begin{array}{l}\text { Anomalies between MAR forced with the ERA-Interim over } 2000-2016 \text { and MAR forced with the } \\
\text { unaltered ERA-Interim reanalysis over } 1980-1999\end{array}$ \\
\hline Anomalies between MAR forced with the ERA-Interim reanalysis warmer of $+1{ }^{\circ} \mathrm{C}$ over $2000-2016$ and \\
MAR forced with the unaltered ERA-Interim reanalysis over $1980-1999$
\end{tabular}


Table S2. Abbreviation description of GCM sensitivity experiments

\begin{tabular}{|c|c|}
\hline MARmir+1 & $\begin{array}{l}\text { Anomalies between MAR forced with MIROC5 over a warmer } 20 \text {-yr period of }+1{ }^{\circ} \mathrm{C} \text { relatively to the reference } \\
\text { period } 1980-1999 \text { and MAR forced with MIROC5 over the reference period }\end{array}$ \\
\hline MA & $\begin{array}{l}\text { Anomalies between MAR forced with MIROC5 over a warmer } 20 \text {-yr period of }+1.5^{\circ} \mathrm{C} \text { relatively to the reference } \\
\text { period } 1980-1999 \text { and MAR forced with MIROC5 over the reference period }\end{array}$ \\
\hline MARmir+2 & $\begin{array}{l}\text { Anomalies between MAR forced with MIROC5 over a warmer } 20 \text {-yr period of }+2{ }^{\circ} \mathrm{C} \text { relatively to the reference } \\
\text { period } 1980-1999 \text { and MAR forced with MIROC5 over the reference period }\end{array}$ \\
\hline MARnor+1 & $\begin{array}{l}\text { Anomalies between MAR forced with NorESM1 over a warmer } 20 \text {-yr period of }+1{ }^{\circ} \mathrm{C} \text { relatively to the reference } \\
\text { period } 1980 \text { - } 1999 \text { and MAR forced with MIROC5 over the reference period }\end{array}$ \\
\hline MARnor+1.5 & $\begin{array}{l}\text { Anomalies between MAR forced with NorESM1 over a warmer } 20 \text {-yr period of }+1.5{ }^{\circ} \mathrm{C} \text { relatively to the reference } \\
\text { period } 1980 \text { - } 1999 \text { and MAR forced with MIROC5 over the reference period }\end{array}$ \\
\hline MARnor+2 & $\begin{array}{l}\text { Anomalies between MAR forced with NorESM1 over a warmer } 20 \text {-yr period of }+2{ }^{\circ} \mathrm{C} \text { relatively to the reference } \\
\text { period } 1980 \text { - } 1999 \text { and MAR forced with MIROC5 over the reference period }\end{array}$ \\
\hline MARcan+1 & $\begin{array}{l}\text { Anomalies between MAR forced with CanESM2 over a warmer } 20 \text {-yr period of }+1{ }^{\circ} \mathrm{C} \text { relatively to the reference } \\
\text { period } 1980-1999 \text { and MAR forced with MIROC5 over the reference period }\end{array}$ \\
\hline MARcan+1.5 & $\begin{array}{l}\text { Anomalies between MAR forced with CanESM2 over a warmer } 20 \text {-yr period of }+1.5{ }^{\circ} \mathrm{C} \text { relatively to the reference } \\
\text { period } 1980 \text { - } 1999 \text { and MAR forced with MIROC5 over the reference period }\end{array}$ \\
\hline MARcan+2 & $\begin{array}{l}\text { Anomalies between MAR forced with CanESM2 over a warmer } 20 \text {-yr period of }+2{ }^{\circ} \mathrm{C} \text { relatively to the reference } \\
\text { period } 1980-1999 \text { and MAR forced with MIROC5 over the reference period }\end{array}$ \\
\hline
\end{tabular}

